Artigo

\title{
EDUCAÇÃO BILÍNGUE A PARTIR DOS MOVIMENTOS \\ SOCIOEDUCACIONAIS DAS PESSOAS SURDAS EM SALVADOR- BAHIA: DIREITOS LINGUÍSTICOS X INCLUSÃO?
}

\author{
BILINGUAL EDUCATION FROM THE SOCIO-EDUCATIONAL MOVEMENTS OF \\ THE DEAF PEOPLE IN SALVADOR- BAHIA: LANGUAGE RIGHTS X INCLUSION?
EDUCACIÓN BILINGÜE DESDE LOS MOVIMIENTOS SOCIOEDUCATIVOS DE LAS PERSONAS SORDAS EN SALVADOR- BAHIA: DERECHOS DEL LENGUAJE $X$ INCLUSIÓN?

\author{
Alex Sandrelanio dos Santos Pereira \\ David Kaique Rodrigues dos Santos
}

\section{Resumo}

O objetivo central deste trabalho é descrever e analisar a existência de um emaranhado de normas jurídicas educacionais que sugiram após a Constituição Federal de 1988, sobre a égide da garantia da igualdade material e o direito à diferença, fruto do embate histórico dos movimentos sociais, especificamente os movimentos socioeducacionais das pessoas surdas, focando na possibilidade jurídica da escola bilingue (Libras e Português escrito). Muito são os debates sobre a educação da pessoa surda no Brasil no que se relaciona à Educação na sua perspectiva inclusiva. Alguns defendem que a educação de surdos deve seguir as novas diretrizes do Ministério da Educação e incluí-los nas salas de aulas regulares e outros, sobretudo a comunidade surda brasileira, uma educação especializada para os surdos. E como o Estado e a sociedade brasileira devem garantir o direito à Educação das pessoas surdas? Através da inclusão nos espaços escolares com pessoas ouvintes ou em escolas especializadas? Se em escolas especializadas, estaria o Estado e a sociedade promovendo segregação ou inclusão? Essa dicotomização refletem o direito linguístico da pessoa surda? A escola Bilingue para a pessoa surda estaria em contradição a educação na perspectiva inclusiva? São perguntas como essas que direcionaram essa produção científica. A metodologia usada é do tipo qualitativa, descritiva e documental. Resultados demonstram que houve uma série de modificações regulamentares que dão suporte a existência de discriminação positiva para a garantia do direito à educação da pessoa surda e a garantia do seu direito à Libras. A conclusão que chegamos é que, baseado nas normas educacionais específicas para as pessoas surdas, sobretudo a Lei 10.436/2002 e seu decreto regulamentador 5.626/2005 cominado com Lei Brasileira de Inclusão e, consagradas no Plano Municipal de Educação de Salvador - PME em sua Meta ํㅡ 4, as escolas e classes bilíngues como a opção jus-educacional para a pessoa surda.

\footnotetext{
Abstract

The main objective of this work is to describe and analyze the existence of a tangle of educational legal norms that suggest after the Federal Constitution of 1988, on the aegis of guaranteeing material equality and the right to difference, as a result of the historical clash of social movements, specifically the socio-educational movements of deaf people, focusing on the legal possibility of bilingual schools (Libras and written Portuguese). There are many debates on the education of the deaf person in Brazil in
} 
relation to Education in its inclusive perspective. Some argue that deaf education should follow the new guidelines of the Ministry of Education and include them in regular classrooms and others, especially the Brazilian deaf community, a specialized education for the deaf. And how should the State and Brazilian society guarantee the right to education for deaf people? Through inclusion in school spaces with hearing people or in specialized schools? If in specialized schools, is the State and society promoting segregation or inclusion? Does this dichotomization reflect the linguistic right of the deaf person? Would the Bilingual school for the deaf person contradict education in an inclusive perspective? These are the questions that guided this scientific production. The methodology used is of a qualitative, descriptive and documentary type. Results demonstrate that there were a series of regulatory changes that support the existence of positive discrimination to guarantee the right to education of the deaf person and the guarantee of their right to Libras. The conclusion we reached is that, based on specific educational norms for deaf people, especially Law 10.436 / 2002 and its regulatory decree 5.626 / 2005 combined with the Brazilian Inclusion Law and enshrined in the Municipal Education Plan of Salvador - PME in its Goal 4, bilingual schools and classes as the jus-educational option for the deaf person.

\section{Resumen}

El objetivo principal de este trabajo es describir y analizar la existencia de una maraña de normas Educativo legal que sugiere después de la constitución federal de 1988, sobre la égida de la garantía de igualdad Material y derecho a la diferencia, el resultado del choque histórico de los movimientos sociales, específicamente los movimentos Educación social de las personas sordas, centrándose en la posibilidad legal de la escuela bilingue (Libras y português Escrito). Muchos son los debates sobre la educación de la persona sorda en Brasil en lo que se relaciona con la educación en su Perspectiva inclusiva. Algunos sostienen que la educación de los sordos debe seguir las nuevas directrices del Ministerio de educación e incluirlos en las aulas regulares y otros, especialmente la comunidad brasileña de sordos, uma Especializado para sordos. Y cómo el Estado y la sociedad brasileña deben garantizar el derecho a la educación de la ¿Personas sordas? ¿A través de la inclusión en espacios escolares con personas auditivas o escuelas especializadas? Si en las escuelas especializadas, ¿el Estado y la sociedad estarían promoviendo la segregación o la inclusión? Éste ¿La dicotomesización refleja el derecho linguístico de la persona sorda? La Escuela Bilingue para personas sordas estaría em ¿Contradicción con la educación desde una perspectiva inclusiva? Estas son preguntas como estas que han dirigido esta producción Científica. La metodología utilizada es cualitativa, descriptiva y documental. Los resultados muestran que hubo Una serie de modificaciones regulatorias que apoyan la existencia de discriminación positiva para la garantia El derecho a la educación del sordo y la garantía de su derecho a Libras. La conclusión que hicimos es que, Sobre la base de las normas educativas específicas para las personas sordas, especialmente la ley 10.436/2002 y su decreto 5.626/2005 regulado con la Ley Brasileña de Inclusión y, consagrado en el Plan Municipal de Educación de Salvador PME en su objetivo No. 4, escuelas y clases bilingues como la opción jus-educacional para La persona sorda.

Palavras-chave: CFRB/88; LDB/96; LBI; Lei da Libras; Escola Bilingue; PME/SSA. Keywords: CFRB / 88; LDB / 96; LBI; Libras Law; Bilingual School; SME / SSA.

Palabras claves: CFRB/88; LDB/96; LBI Ley de Libras; Escuela Bilinguista; PME/SSA.

\section{EDUCAÇÃO BRASILEIRA E SUA PERSPECTIVA SURDA}


O direito à Educação no Brasil é permeado por um consistente emaranhado de normas jurídicas, encontrando na Constituição Federal de 1988 sua base principiológica, sendo compreendido como um direito fundamental para instrumentalizar outros direitos.

Já no artigo 6ำ do texto constitucional brasileiro a Educação aparece no rol dos direitos sociais e, portanto, conforme o artigo 205 do mesmo diploma magno, como um direito de todos e um dever do Estado.

Ainda sobre o manto constitucional e aproximando da temática desse trabalho temos a previsão da garantia da educação especial, agora sobre a perspectiva da inclusão, no artigo 208. Não é de hoje que o surdo vem travando lutas para romper as barreiras ainda existentes, para conseguir acesso a uma educação em condições iguais a dos ouvintes.

O surgimento da Língua Brasileira de Sinais - Libras, está no contexto da História dos surdos no Brasil desde 1857, quando a convite de D. Pedro II, o professor surdo Eduard Huet, fundou a primeira escola para surdos no País (MORI; SANDER, 2015, p.1), ocorre que, mesmo após anos de lutas, seu reconhecimento como uma segunda língua oficial no Brasil só se deu em 2002, através da Lei № 10.436 (BRASIL, 2002).

Um dos dilemas contemporâneos sobre a educação de surdos é saber o "lugar" apropriado para possibilitar a pessoa surda escolarização e que de certa forma nos impulsionar a questionar o modelo monoespacial em que a representação de escola e educação está assentada para projetar "educações", no plural e num sistema inclusivo, visando alcançar sujeitos e suas especificidades educacionais, efetivando garantias de aprendizagens fundamentais, na produção dos sujeitos brasileiros no exercício da cidadania e democracia.

Existem argumentos que a educação da pessoa surda no Brasil deve acontecer nas escolas e classes regulares, conjuntamente com os alunos ouvintes, em respeito à perspectiva "inclusiva" da educação brasileira. É nesse entendimento que as políticas públicas educacionais elaboradas pelo Ministério de Educação e Cultura (MEC) vêm orientando, conforme podemos extrair do Decreto de no 6.094/2007, por exemplo.

Já os movimentos sociais surdos no Brasil em prol da educação defendem a institucionalização das escolas e classes bilíngues como a melhor alternativa para o processo de escolarização da pessoa surda, em respeito à sua especificidade linguística (L1 - Libras e a L2- a escrita e leitura do língua portuguesa), ou seja, que todo o processo educacional da pessoa surda aconteça em Libras, como língua de instrução, e que a língua portuguesa, leitura e escrita dessa, seja ensinada numa metodologia específica de $2^{\underline{a}}$ língua, para que essa suposta "inclusão" não seja uma falácia (BENTO, 2009).

O ponto mais pacífico entre essa dicotomização é no reconhecimento que a Libras é uma língua, com estrutura e gramática própria, em função da Lei Federal 10.436/2002 e do Decreto 5.626/2005 que a regulamentou.

E como o Estado e a sociedade brasileira devem garantir o direito à Educação das pessoas surdas? Através da inclusão nos espaços escolares com pessoas ouvintes ou em escolas especializadas? Se em escolas especializadas, estaria o Estado e a sociedade promovendo segregação ou inclusão? Essa dicotomização refletem o direito linguístico da pessoa surda? A 
escola Bilíngue para a pessoa surda estaria em contradição a educação na perspectiva inclusiva?

São perguntas que surgem a fim de direcionar essa produção científica que, demonstrando intenções sociopolíticas, aponta para pensarmos a escola e educação na sua perspectiva plural, democrática e que os movimentos sociais surdos devem atuar para que o Estado, a sociedade, a comunidade, a escola, a família e os sujeitos individuais sejam plurais e democráticos em suas produções existenciais.

Assim estaremos diante de uma nova postura educativa que respeita e media processos de cidadanias, no plural e na diversidade, sob a égide dos princípios jus- educacionais do Brasil produzidos em função da especificidade da pessoa surda, em busca de uma educação inclusiva a partir da escola bilíngue para a pessoa surda, como passaremos a descrever e analisar.

\section{PLURALIDADE EDUCATIVA E O DIREITO À DIFERENÇA LINGUÍSTICA DA PESSOA SURDA}

A Educação não deve mais ser pensada numa dimensão monocultural, mas pensar educações pluriculturais e suas multiplicidades de sujeitos e modos de educação que, a partir da perspectiva inclusiva e em diálogo e respeito à diferença, normatizou o direito da pessoa surda à língua, que no caso brasileiro, o direito à Libras.

No entanto, nossa realidade reflete a nossa representação social de escola, no singular, daí enfrentamos por muito tempo uma perspectiva universalista de educação, um modelo único, que não dá conta de cumprir o dever constitucional do Estado de garantir o direito à Educação a todas e todos, muito menos por causa de suas dimensões territoriais (discurso muito sustentado), mas pela exclusão e epistemicídio de povos e raças ; então, passou-se a vislumbrar uma perspectiva de educação mais plural, que atendesse essa diversidade de sujeitos, que em busca de reconhecimento do Estado e não da sociedade, pois eles também são parte dessa sociedade, mas, do Estado, esse ente político que é responsável por executar políticas públicas e trazer para os projetos políticos modos e formas de atender essas demandas.

Sendo assim, passa a existir múltiplas maneiras e não mais uma só forma de pensar a educação; não só pensar a escola inclusivista como modelo único. Existem diferentes maneiras e nesse artigo discutiremos um pouco sobre essas múltiplas formas reguladas em normas e esses múltiplos sujeitos para compreendermos como é possível pensar mais uma forma de olhar esse outro sujeito que é o surdo, sem entrar nessa dicotomia de estarmos promovendo novamente segregação, promover a efetiva inclusão.

\section{Educação na perspectiva inclusiva}

É no contexto de Direitos Humanos, que perpassar por todos os modelos educacionais, que o Estado vai elaborando normatividade em diálogo com o movimento internacional do direito de todos à educação e, trazendo para o campo de política educacional, que estamos hoje sob o império da perspectiva educacional inclusiva. 
Quando estamos discutindo a educação na perspectiva inclusiva, não estamos aqui apenas tratando de pessoas com deficiência; o objetivo de pensar a perspectiva inclusiva, é dizer que há um sistema educacional, que era exclusivo para determinados sujeitos e que ele produzia exclusão e é claro que a pessoa com deficiência sentia muito mais essa exclusão. Mas, não somente essas pessoas com deficiência estão/estavam excluídas do sistema educacional, daí porque foi-se pensar a educação quilombola, a educação no campo, a educação de pessoas em condição de itinerância, a educação indígena e etc.

Então, não somente as pessoas com deficiência e sim vários outros sujeitos passaram/passam por um processo de exclusão escolar.

Dessa forma, a perspectiva inclusiva vem justamente no sentido de conectar sujeitos numa relação de pertencimento ao modelo educacional. E de que forma isso vai acontecer? Esses sistemas educacionais têm que se modificar, de maneira a sofrer adequações a novas possibilidades de pertencimento, de diversos sujeitos que estão num contexto vivencial que demanda para o Estado, um tipo específico de educação.

Diferentemente de pensar a educação especial como segregação, é pensar a educação inclusiva que perpassa por todos os modelos educacionais inclusive a educação especial, e aí sim, o modelo de educação especial foi construído sobre uma ótica de atendimento a pessoa com deficiência, entendendo na sua própria estruturação e elaboração, as especificidades que cada deficiência traz.

Por outro lado, era reconhecido que havia um deslocamento entre aquilo que o Estado trazia como componente de formação curricular para o sujeito na sua forma mais universal e criava- se uma estrutura curricular minimizando conteúdos e isso ia sendo repassado para uma perspectiva de educação especial.

A educação inclusiva fez uma conexão entre o que é educação e o que é educação especial e trouxe esses dois componentes para um diálogo mais intenso.

Não se pode admitir que dentro dos componentes da educação haja separação para ter acesso mínimo; a ideia de ter diversos sujeitos e diversas maneiras de se produzir educação é mais no sentido de proteger e garantir o acesso pleno a educação do que diminuir o acesso desse sujeito. Claro é que, quando se está diante de casos específicos, é necessário que haja uma lógica diferenciada de pensar essa educação e o seu conceito de qualidade.

Muitas vezes se vai para o discurso de que quem promove uma educação de qualidade, seria aqueles cujo os alunos obtém as melhores notas no Enem, portanto, que acessam as universidades; aqueles que estão diante da possibilidade de terem uma vida plena sozinhos, autônomos. Mas, temos diversos sujeitos que estão numa dinâmica que vivencia outras realidades.

O que se pensa sobre a perspectiva inclusiva é essencialmente, perceber que o sujeito que está na educação de surdos que tem como base a Libras, por exemplo, uma criança ouvinte que deseje e saiba língua de sinais, possa estar naquela escola. A educação inclusiva, perpassa por todos os modelos, inclusive para aquele que se especializa.

Dessa forma, se há um sujeito que mora na cidade e a família decide viver um outro ambiente social e deseje mudar para o campo, vivenciar a 
experiência do campo, a educação do campo é o melhor modelo para esse sujeito que tem uma nova demanda.

Não se pode confundir assim a ideia de uma educação inclusiva para pensar somente a pessoa com deficiência pois, a ideia do modelo inclusivo, é uma ideia filosófica de fazer com que sujeitos pertençam aquilo que tem de melhor, de mais qualidade, aquilo que a sociedade produziu que garanta acesso pleno a um museu, a escola, aos seus direitos políticos, aos seus direitos civis, a segurança, a educação que todo sujeito tem, sem confundir isso com um campo unificado ou seja, agora a educação é de uma determinada forma e isso se aplica para todos independente de quem seja.

Então não é esse modelo que deve ser pensado para uma educação inclusiva, pelo contrário, é fazer com que se construa novos modos que atenda a demanda e que garanta a ele o mínimo de currículo de formação acadêmica.

Claro que para isso o Estado também vai pensar diretrizes operacionais para organizar por exemplo, como fazer isso.

Podemos dizer que a educação agora está numa perspectiva inclusiva e o Estado, sozinho, não possui a capacidade técnica de garantir como isso vai acontecer. Então o Estado também vai elaborar propostas e documentos, com a participação da sociedade civil organizada, que vão dizer como serão essas diretrizes operacionais para inclusão.

Nesse caso é imprescindível considerar conhecimentos básicos sobre esses sujeitos tais como, que para o surdo tem que ter o acesso a Libras, para a pessoa cega tem que ter um brailista, para a pessoa surdo-cega tenha um tradutor intérprete da Libras tátil, partindo daí para criar outras diretrizes como o funcionamento das salas multifuncionais. Só que, essas perspectivas acontecem de forma generalista, sendo assim, é preciso criar outras formas em que essa educação aconteça na coletividade sem perder a garantia de qualidade para determinados sujeitos cuja condição física, cognitiva, comportamental, cultural etc demandem uma educação especializada.

No bojo dessa construção de políticas educacionais, nessa construção de pensar os dispositivos legais que garantam maior proteção as pessoas, sobretudo as pessoas com deficiência e, em específico aqui, a pessoa surda, é que se discute e defende uma educação da pessoa surda. Quanto a isso, vários estudos vão demonstrar e demarcar como se dá a educação da pessoa surda, qual o melhor modelo no que se refere a eficácia, garantia dos princípios fundamentais da educação, consagrando a escolas e classes bilíngues como a melhor estratégia de garantir o direito linguístico e o direito à educação formal no Brasil.

Em razão desses fundamentos anteriormente apresentados é que o Ministério da Educação, o Conselho Nacional de Educação, Os Conselhos Estaduais de Educação, os Conselhos municipais de Educação e o Conselho distrital de Educação irão normatizar uma série de diretrizes e metas para que seja concretamente materializada as diversidades educacionais e que, diante das pessoas com deficiência passa admitir uma dupla jornada:

[...] trajetória de exclusão e segregação das pessoas com deficiência, alterando as práticas educacionais para garantir a igualdade de acesso e permanência na escola, por meio da matrícula dos alunos público alvo da educação especial nas 
classes de ensino regular e da disponibilização do atendimento educacional especializado. (BRASIL, 2010, p. 7)

Assim, as e os discentes com deficiência tem a garantia da estudar, de forma prioritária em classes "regulares" e o direito do Atendimento Educacional Especializado (AEE). Esse direito constitucional ao AEE deve ser garantido, mesmo em escolas especializadas como as escolas e classes bilíngues para as pessoas surdas.

\section{História e resistência: movimentos sociais surdos em prol da educação bilíngue}

As lutas e as resistências que os movimentos sociais das pessoas surdas realizaram ao longo do tempo produziram narrativas que moldaram sua concepção de história, tomando para si o protagonismo dessa escrita e seus marcadores, cujo objetivo é enfrentar a invisibilidade, uma perspectiva cultural que o inferioriza e, afirma-se como Eu legítimo a falar sobre si, em articulações identitárias e políticas.

Essas narrativas e reflexões acadêmicas na seara das ciências humanas e sociais, a exemplo a ciência da educação, são batizadas de "Estudos Surdos".

No campo da Educação e da Linguística temos diversas autoras surdas que passaram a focalizar os estudos da Libras e os processos de aprendizagem da pessoa surda, realizando uma revolução interpretativa no campo da surdez que conduziram a diversas alterações nas políticas públicas educacionais para as pessoas surdas, como exemplo podemos citar Larissa Rebouças (2009), Regina Maria de Souza (1998) e Patrícia Luiza Ferreira Rezende $(2010)^{1}$ descreveram a pessoa surda em relação a pessoa surda, demarcando a diferença linguísticas que as constituem e as implicações linguísticas que isso produz.

Diversas são as terminologias externas utilizadas para etiquetar a pessoa surda no mundo social: "mudo"; "muda"; "mudinha"; mudinho; "surdamuda"; "surdo-mudo"; "deficiente auditivo". Elas têm em comum a origem, ou seja, são as pessoas ouvintes que assim a denominam, baseando-se em desconhecimentos e preconceitos, oscilando entre a perspectiva de ausência e de falta, que na crença médica e científica são reparadas pelas tecnologias dos aparelhos auditivos ou dos implantes cocleares.

Já nos dispositivos legais atuais encontramos expressões como "Pessoa surda" e "deficiência auditiva" (art. $2^{\circ}$, caput e parágrafo único, do Decreto $5.626 / 2005)$ Os movimentos sociais surdos passaram a adotar o termo "surda" ou "surdo", muito usual entre as pessoas surdas, que os têm como uma marca identitária importante na sua luta linguística, sua cultura e processos históricos.

A terminologia surdo/surda é uma reinvindicação do sujeito que passa a lutar politicamente para poder se auto representar e enunciar sua identidade linguística, sua historicidade e sua comunidade cultural.

\footnotetext{
1 Houve uma busca pela epistemologia surda, ou seja, escolha de teóricas surdas que escrevem sobre o processo educativo das próprias pessoas surdas. Mulheres surdas teóricas da Educação.
} 
Faz-se necessário ressaltar que essa alteridade é construída num complexo jogo de interação entre pessoas surdas e não surdas, sendo essa diferenciação a mola propulsora de leitura e interpretação da realidade social e educacional em que a comunidade surda está inserida, produzindo uma série de artefatos culturais de sobrevivência, a qual Gesser (2006) chamou de "situação de emergência".

Nesses diversos encontros entre surdos e ouvintes no mundo social, alguns passaram a conviver organicamente com esses movimentos socioculturais surdos, o que levará a pesquisadora surda Karen Strobell (2009) estabelecer distinções entre os surdos e os ouvintes fluentes em Libras. Segundo essa autora a comunidade surda seria a forma mais ampliativa em, que pessoas surdas e não surdas fluentes em Libras, participam ativamente da agenda sociocultural e política dos movimentos, assim como, pesquisadores no campo da surdez que contribuem para a reflexão acadêmica da comunidade surda. Já o povo surdo é composto exclusivamente de pessoas surdas, adquiridas ou nascidas, que vivem e sentem toda a complexidade da surdez.

Muitos não surdos acreditam que a questão da pessoa surda se resolveria com método de oralização eficaz, levando-os a crença que toda pessoa surda é capaz de fazer leitura labial.

Essa crença é compatível com a história da educação dos surdos, que toma como marco histórico o Congresso de Milão de $1880^{2}$ para estabelecer os métodos educacionais e seus pressupostos teóricos no processo de escolarização da pessoa surda.

Os três métodos educacionais para os surdos são o Oralismo, a Comunicação total e o Bilinguismo.

No método oralista, que os estudos surdos apontam que o Congresso de Milão de 1880 aprovou a forma pura, ou seja, a proibição da língua de sinais e somente o uso da língua oral e escrita, entendendo que essa era a melhor estratégia metodológica de ensinar e dos surdos aprender as diversas áreas de conhecimentos.

Anteriormente aos efeitos dessa decisão em Milão havia o uso combinado entre as duas línguas, sendo que o objetivo era que os surdos aprendessem a língua do seu país.

As pessoas surdas se organizaram, resistiram e lutaram para que a língua de sinais continuasse viva, mesmo diante da proibição do uso da língua de sinais nos espaços escolares, há relatos que os meninos surdos do INES, na época de sua proibição naquela instituição, usavam o banheiro para continuar a usá-la.

\footnotetext{
${ }^{2}$ Ainda que seja uma tradição mencionar seu caráter decisivo, o Congresso de Milão, de 1880 onde os diretores das escolas para surdos mais renomadas da Europa propuseram acabar com o gestualismo e dar espaço à palavra pura e viva, à palavra falada- não foi a primeira oportunidade em que se decidiram políticas e práticas similares.[...] Apesar de algumas oposições, individuais e isoladas, o referido congresso constituiu não o começo do ouvintismo e do oralismo, mas sua legitimação oficial [...] o ouvintismo, ou o oralismo, não pode ser pensado somente como um conjunto de ideias e práticas simplesmente destinadas a fazer com que os surdos falem e sejam como os ouvintes. Convivem dentro dessas ideias outros pressupostos: os filosóficos - o oral como abstração, o gestual como sinônimo de obscuridade do pensamento; os religiosos - a importância da confissão oral, e os políticos - a necessidade da abolição dos dialetos, já dominantes no século XVIII e XIX (SKLIAR, 2010, p. 16-17).
} 
Depois veio a Comunicação total que tinha o propósito de levar o conhecimento aos surdos através da interação e da comunicação, admitindo novamente a língua de sinais, não como uma língua de instrução, mas como uma estratégia educativa.

Não preciso mencionar que ambos não conseguirem efetivar o acesso pleno e igualitário das pessoas surdas aos conteúdos curriculares escolares e, atualmente, estamos sobre a bandeira política da educação bilingue para as pessoas surdas, entendendo que seu processo educacional deve acontecer na sua língua de instrução, ou seja a Libras, mas deve também desenvolver a língua portuguesa, como sua segunda língua (Lei 10.436/2002).

Entendemos que língua e cultura estão imbrincadas, portanto, a Libras enquanto língua produz cultura, ou seja, artefatos culturais próprios da comunidade surda.

A cultura surda, defendida nesse trabalho, diz respeito as construções materiais e imateriais que a comunidade surda mundial e brasileira forjou/forjará ao longo da sua historiografia, que nos permite ver e interpretá-la:

O conceito de cultura que eu defendo é essencialmente semiótico. Acreditando, como Max Weber, que o homem é um animal amarrado às teias de significados que ele mesmo teceu, assumo como cultura como sendo essas teias e suas análises, portanto, não como uma ciência experimental em busca de leis, mas como uma ciência interpretativa, à procura de significado (GEERTZ, 1973, p.15).

Em sintonia com o que a teórica surda Karen Strobel escreveu no seu livro "As imagens do outro sobre a cultura surda" ao descrever o que seria a cultura surda:

O jeito de o sujeito surdo entender o mundo e modificá-lo a fim de torná-lo acessível e habitável ajustando-o com suas percepções visuais, que contribuem para a definição das identidades surdas. [...] Isso significa que abrange a língua, as idéias, as crenças, os costumes e os hábitos do povo surdo. (STROBEL, 2009, p. 27).

Neste mesmo livro a autora surda estabelece oito artefatos culturais da cultura surda: experiência visual, linguístico, familiar, literatura surda, artes visuais, vida social, esportiva e político.

$\mathrm{Na}$ sequência demonstrará diversos criações e adaptações materiais que irão demarcar a existência de uma cultura que se constituiu em torno da língua de sinais.

Essas diversas experiências também marcará as diversas culturas e línguas de sinais existentes no Brasil com seus regionalismos, como mencionamos no capítulo II, a existências de língua de sinais nas comunidades indígenas brasileiras, nos remanescentes de quilombos, entre os povos ciganos etc.

Uma pena que Strobel não trouxe a escola bilíngue como um dos artefatos culturais da cultura surda porque ela resultado material e imaterial da 
luta surda contra as diversas tentativas de "normatização" da pessoa surda tomada como parâmetro a pessoa ouvinte.

Um dos principais princípios constitucionais da educação é o princípio da participação cidadã, na construção e elaboração de políticas educacionais, sendo que sua concretização deve ser material, com produções efetivas. Aliado a esse princípio fundamental temos a base epistemológica da educação de surdo que é o direito linguístico a Libras.

Os estudos vêm demonstrando que a grande maioria das crianças surdas nasce e é criada em lares em que seus pais são ouvintes e desconhecem a língua de sinais.

Neste contexto a possibilidade de representação de ter uma criança surda é quase nula e toda a representação da criança que virá é constituída num imaginário de criança que escuta e ouve. Antes mesmo de inaugurar sua existência física autônoma de sua mãe, a criança já está pautada num universo de oralidade:

\begin{abstract}
"O filho surdo de ouvintes começa a ser nomeado muito antes de nascer, sem que seus pais saibam que será surdo... a criança surda antes de nascer já se constitui em enunciador dentro do funcionamento da língua oral, ainda sem ser locutor. Começa a ser falada por uma língua oral e logo será sujeitada a ela, língua que nunca lhe poderia devolver a imagem de que é dono de seu dizer, na medida em que não a pode falar nem sequer escutar plenamente. Esta situação continuará por muito tempo depois de ter nascido, sendo um enunciador (através de sua inscrição na enunciação dos pais) sem conseguir constituirse em um locutor. Assim, o surdo filho de pais ouvintes fica em posição de escravo frente a uma língua que faz dele um estrangeiro em relação ao sistema que o atravessa e o estrutura. Diferentemente de quem é estrangeiro em relação a uma língua na qual não se instaura como sujeito (mas que possui sua própria língua materna), o surdo filho de ouvintes é estrangeiro em relação à própria língua materna. Isto ocorre porque o surdo não pode deixar de constituir-se em escravo em relação a uma língua que o exclui duplamente: o separa e o exclui de toda possibilidade de sentir-se um sujeito dono do seu dizer". (BEHARES e PELUSO, 1997, p.43)
\end{abstract}

Um grande problema para uma criança surda que nasce em um lar que desconhece a língua de sinais é o empobrecimento da mediação dos símbolos culturais, sobretudo, das relações interacionais e sociais.

Primeiramente é ela um organismo fisiológico, com seus mecanismos e exigências biológicas. Além disso, é uma entidade psicológica subordinada ás leis psicológicas do pensar, do sentir, do interpretar e do agir. Mas do que tudo, porém, a criança é um ser social, que deseja pertencer a vida grupal e age de acordo com a atmosfera desse grupo. Em qualquer idade, suas necessidades básicas só serão satisfeitas se a criança tiver oportunidade para funcionar adequadamente em todos esses três níveis de desenvolvimento (DREIKURS, 2001). 
A família é a primeira dimensão da relação social da criança e no caso dos surdos, em que não há o feedback pela oralidade e da ausência da língua de sinais, as compreensões estão centradas na leitura das expressões faciais que seus pais fazem, numa dicotomia binária entre o gostar e não gostar, embora constitua uma relação de proximidades, é uma proximidade empobrecida de multiplicidades de contextos sociais complexos que uma família contemporânea está submetida.

Não podemos pensar o desenvolvimento psicológico como um processo abstrato, descontextualizado, universal: o funcionamento psicológico, particularmente no que se refere às funções psicológicas superiores, tipicamente humanas, está baseado fortemente nos modos culturalmente construídos de ordenar o real (OLIVEIRA, 1993:24)

A escola é o espaço privilegiado para desenvolvimento das competências acadêmicas que a modernidade produziu e que coadunam com os modelos de ser humano e civilidade que politicamente se consolidou através dos currículos e do direcionamento que a sociedade projeta para ser futuro.

Uma instituição da necessidade humana, em virtude de vivermos relações humanas e modos de vida baseados no pensamento científico, que produzem um ser humano em processo de inscrição cultural, sendo para tanto, usado estímulos e proibições, que no caso dos surdos torna-se um lugar onde a desigualdade de oportunidade e aprendizagem irá aumentar o fosso entre eles e seus amigos ouvintes.

Entretanto, em se tratando da educação dos surdos no Brasil, o que há são processos educacionais permeados de incertezas, como a que descreveu uma educadora surda sobre seu processo de escolarização:

Os meus colegas não me aceitavam porque tinham receio que a surdez pegasse como uma doença contagiosa, eles tinham medo de falar comigo, achando que eu não iria compreender, sempre que estava na fila por ordem de chegada, às vezes a primeira, por morar próximo à escola, eles me puxavam pelos meus longos cabelos negros que estavam trançados como uma índia, me arrastavam e colocavam como última da fila; sem entender muito bem, eu aceitava as imposições. (VILHALVA, 2001, p.19)

Muitos relatos demonstram que os espaços escolares inclusivistas não estão preparados para pensar as especificidades dos surdos e que:

(...) a quantidade e a qualidade de informações e assuntos abordados são muito inferiores àqueles que os indivíduos ouvintes, em sua maioria, recebem e trocam. Os surdos, nestas condições, só conseguem expressar e compreender assuntos do aqui e agora. Para falar sobre situações passadas, lugares diferentes e, principalmente, sobre assuntos abstratos são quase impossíveis - se realmente não o for (...)". (GOLDFELD, 2002, p.62) 
Isso se dá porque necessita que um adulto mediasse seu processo de aprendizagem escolar, alguém que identificasse sua necessidade e qual 0 domínio que ela possuía para traçar novas conquistas acadêmicas:

[...] Porque na escola a criança não aprende o que sabe fazer sozinha, mas o que ainda não sabe e the vem a ser acessível em colaboração com o professor e sob sua orientação. 0 fundamental na aprendizagem é justamente o fato de que a criança aprende o novo. Por isso a zona de desenvolvimento imediato, que determina esse campo das transições acessíveis à criança, é a que representa o momento mais determinante da relação da aprendizagem com o desenvolvimento (VIGOTSKI, 2000, p. 331)

Uma primeira marca de diferenciação educacional a ser discutida, então, em relação à surdez, sendo fonte principal de sua alteridade, está no binário surdo versus ouvinte. Um universo linguístico que:

(...) sistemas lingüísticos que passaram de geração em geração de pessoas surdas. São línguas que não se derivaram das línguas orais, mas fluíram de uma necessidade natural de comunicação entre pessoas que não utilizam o canal auditivooral, mas o canal espaço- visual como modalidade lingüística. (QUADROS, 1997, p.47)

Se analisarmos esses termos por uma categoria exclusivamente fisiológica não poderíamos visualizar essa contraposição, pois pautada no aspecto de ausência da capacidade de ouvir, teríamos apenas a pessoa surda. Por outro lado, fruto das reivindicações políticas da comunidade surda, essa diferenciação se dá num complexo jogo antropológico:

(...) a língua é uma importante característica definitiva. Diferente da cegueira ou da incapacitação ligadas ao movimento, por exemplo, a surdez é invisível. Ela só se torna visível quando a pessoa surda se envolve em alguma ação comunicativa. O grupo de pessoas surdas define-se como "uma população cuja capacidade distintiva consiste no uso necessário de um sistema lingüístico que não exige comunicação auditiva/oral. (SILVA, 1997 p.10)

Para haver comunicação dos surdos com os ouvintes foi necessário que dentre os ouvintes surgissem pessoas, que fossem capazes de se comunicar com a pessoa surda, podendo assumir o papel de colaborar com os surdos para esses se comunicarem com os ouvintes não falantes da língua de sinais; assim como destes ouvintes para com os surdos, os chamados intérpretes de sinais, que estão no seio da chamada comunidade surda e, portanto, compreende o povo surdo em sua plena capacidade:

Devido à existência de uma comunidade de surdos com sua própria linguagem e cultura, existe um âmbito cultural, no qual ser-se surdo é não ser-se incapaz, muito pelo contrário, ser-se 
surdo no comportamento, valores, conhecimentos e ser-se fluente em ASL é considerado, como já vimos, um privilégio na cultura surda. Se respeitarmos os direitos dos cidadãos de outras culturas, incluindo aqueles que fazem parte do nosso país, a terem as suas próprias normas regulamentares, as quais podem ser diferentes das normas (podendo, contudo, recusar fazê-lo, correndo o risco de estarmos a ser ingênuos, apenas por que acreditamos que tal não é possível), então também devemos reconhecer que a surdez da qual falo não é uma enfermidade, mas apenas outro modo de estar e de ser. (LANE, 1992, p. 35).

O surdo ainda era, e muitas vezes ainda o é compreendido como o sujeito kantiano (HALL, 2003), puramente racional e que basta fazer a tradução linguística da língua portuguesa para a Libras que o surdo "dará conta" de compreender sozinho os conteúdos técnicos-científicos. Uma concepção de educação bancária da surdez, que não possibilita ao surdo ser mais.

O ser surdo, aqui, é a-histórico, sem vida, engendrado em concepções abstratas de sujeitos, impossibilitado de dizer a palavra.

Neste sentido que devemos pensar o Projeto Político Pedagógico como um documento que materializa as construções sócio-históricas da educação dos surdos, demarca seus pressupostos pedagógicos e, conforme Gadotti:

Todo projeto supõe rupturas com o presente e promessas para o futuro. Projetar significa tentar quebrar um estado confortável para arriscar- se, atravessar um período de instabilidade e buscar uma nova estabilidade em função da promessa que cada projeto contém de estado melhor do que o presente" (2001, p. 37).

Aliado a isso, precisamos compreende que o PPP de uma escola delimita uma dimensão do currículo que, como bem observou Passos, "O primeiro é de que o currículo não é um instrumento neutro" (Passos, 1995, p.27), portanto, revela o posicionamento racional e tomada de posição.

Embora não seja parte analítica deste trabalho, faz-se necessário citar a outra dimensão em razão dele ser demonstrada no uso social da língua naquele espaço que iremos descrever, pois o currículo oculto "estimula a conformidade a ideais nacionais e convenções sociais ao mesmo tempo em que mantêm desigualdades socioeconômicas e culturais" (Veiga, 1995, p. 28).

Amparando o discurso clínico-patológico da deficiência e não normalidade do surdo, vão se somar aí discursos religiosos e até mesmo pedagógicos, levando as famílias a insistirem no ideal da escuta e da oralidade. Os pais alimentam o mesmo ideal de normalidade que a medicina persegue para os surdos.

A escola, que é parte constituída e constituidora da vida social, também reproduz essas mesmas marcas que a família busca: a normalidade do sujeito. Hoje podemos compreender a surdez por um viés da diferença, entendendo a sociedade como heterogênea. Entretanto, não podemos ser ingênuos de acreditar que velhas expressões e representações sobre a surdez não mais conviva em nossa sociedade, em nossa família e, especificamente no nosso caso, na escola! 
O que nos conforta mais é nos depararmos com a convicção que o protagonista dos movimentos sociais surdos apontam para uma virada identitária surda, pois cada vez mais os surdos, em seus diversos arranjos sociopolíticos, vêm construídos espaços de diálogos e de enfrentamentos as representações negativizantes e a escola não deve e nem vai ficar alheio a isso, principalmente pelo império da lei que consagrou a escolas e classes bilíngue para as pessoas surdas, como veremos.

\section{PROCEDIMENTOS METODOLÓGICOS}

A metodologia do trabalho, tem como primeiro ponto, uma revisão bibliográfica; dar-se-á diante dos conceitos do que é educação, em sua pluralidade existencial, perpassando por mudanças juris-educacionais de garantia a igualdade material e o direito a diferença, chegando à educação da pessoa surda, como ela funciona e foi pensada na história, para depois apresentar a legislação brasileira voltada a garantir a educação especializada da pessoa surda, portanto, documental. Por isso, se caracteriza como uma pesquisa qualitativa, exploratória, descritiva, com procedimento técnico documental (GIL,2008), mais especificamente, das normas jus- educacionais específica para a pessoa surda.

Os instrumentos utilizados serão livros, artigos especializados e as leis.

Embora haja o entendimento de que esse trabalho poderia se dá numa pesquisa de campo, em razão de algumas restrições temporais, esse estudo ficará reservado para uma etapa futura, pensando na continuidade desse projeto em promover um debate político na construção de uma proposta de regime jurídico próprio para a educação de surdos em diálogos com os movimentos sociais surdos em salvador.

No entanto, a tessitura deste trabalho permanecerá na perspectiva histórico-cultural por entendermos que a dimensão histórica e social dos sujeitos se verifica também nas coisas que ele produziu, como bem observou Foucault no livro "As palavras e as coisas" em 1967.

\section{RESULTADOS E DISCURSÃO}

A lei 9.394/96 reservou um capítulo específico para tratar da Educação das pessoas com deficiência, positivando normas educacionais importantes para a garantia do direito à educação.

Embora não trate do tema da educação da pessoa surda de forma específica, essas normas educacionais voltadas as pessoas com deficiência de forma genérica trouxeram impactos nas políticas educacionais voltadas para a pessoa surda.

Logo no seu artigo $4^{\circ}$, que sofreu alteração com a redação dada pela Lei no 12.796/2013 ampliando a titularidade, reitera a previsão constitucional do atendimento educacional especializado.

O Ministério da Educação (MEC), objetivando uma melhor formação aos profissionais do ensino, produzirá alguns materiais com o foco no "Atendimento Educacional Especializado para alunos com surdez" já sobre a égide da Lei 10.436/2002 e do Decreto 5.626/2005, ratificando a natureza bilingue desse atendimento: 
Ao optar-se em oferecer uma educação bilíngue, a escola está assumindo uma política linguística em que duas línguas passarão a coexistir no espaço escolar. Além disso, também será definido qual será a primeira língua e qual será a segunda língua, bem como as funções em que cada língua irá representar no ambiente escolar. Pedagogicamente, a escola vai pensar em como estas línguas estarão acessíveis às crianças, além de desenvolver as demais atividades escolares. As línguas podem estar permeando as atividades escolares ou serem objetos de estudo em horários específicos dependendo da proposta da escola. Isso vai depender de "como", "onde", e "de que forma" as crianças utilizam as línguas na escola. (MEC/ SEESP, 2006)

Algumas considerações se fazem necessárias sobre a perspectiva bilíngue da educação de surdos, muitas vezes confundida com a presença de interprete de Libras $^{3}$ na sala de aula em que o aluno esteja presente.

Conforme Decreto 5.626/2005 o intérprete de Libras é função distinta do professor (Artigo 14, $\S^{\circ}$ ) e atua na sala de aula para proporcionar aos estudantes surdos acesso ao conhecimento (Artigo 21, $§ 1^{\circ}$, Incisos II e III). Não sendo esse profissional, por si só, o que configuraria a educação bilíngue para surdos.

A presença do interprete educacional de Libras é emblemático nessa garantia da educação bilíngue haja vista uma série de problemática que envolve o processo socio acadêmico da pessoa surda.

Crianças surdas, filhas de pais ouvintes, chegam no ambiente escolar com sinais caseiros, que diferentemente da Libras, é estabelecido no seio familiar (GEDIEL, 2010), sendo, portanto, o interprete de Libras, no segmento da educação infantil e do fundamental I, uma política educacional ineficaz no acesso as informações.

No segmento do Fundamental II e Ensino Médio, quando os adolescentes e jovens surdos já são fluentes em Libras, uma nova problemática se inseri: as especialidades das disciplinas escolares e a possibilidade de a interpretação em Libras garantir esse acesso ao conhecimento. Isso acontece porque na prática temos um interprete de Libras para cada sala de aula em que o aluno surdo esteja presente, o qual fará a interpretação das diversas áreas do conhecimento de forma simultânea a explicação do professor, necessitando que o mesmo tenha domínio teórico nas diversas matérias escolares, que acreditamos ser uma tarefa muitíssimo difícil de acontecer na prática.

\footnotetext{
${ }^{3}$ Tradutor-intérprete de língua de sinais - Pessoa que traduz e interpreta a língua de sinais para a língua falada e vice-versa em quaisquer modalidades que se apresentar (oral ou escrita).

Tradução-interpretação simultânea - É o processo de tradução- interpretação de uma língua para outra que acontece simultaneamente, ou seja, ao mesmo tempo. Isso significa que o tradutor-intérprete precisa ouvir/ver a enunciação em uma língua (língua fonte), processá-la e passar para a outra língua (língua alvo) no tempo da enunciação.

Tradução-interpretação consecutiva - É o processo de tradução-interpretação de uma língua para outra que acontece de forma consecutiva, ou seja, o tradutor-intérprete ouve/vê o enunciado em uma língua (língua fonte), processa a informação e, posteriormente, faz a passagem para a outra língua (língua alvo). (MEC/SEESP, 2004, p. 10)
} 
A presença do intérprete de Libras deve estar associada com outros profissionais que irão garantir o direito educacional da pessoa surda, como por exemplo, o instrutor surdo adulto que irá possibilitar que crianças surdas, adolescentes e jovens surdos possam ganhar fluência em Libras de forma interativa com seus pares linguísticos, de forma mediada e sistematizada.

Além disso, conforme a Lei 10.436/2002 e da sua regulamentação através do Decreto 5.626/2005, é obrigatório que a língua portuguesa seja respeitada e ensinada na sua modalidade escrita, mas como uma segunda língua:

No que diz respeito ao aprendiz-surdo, a situação em que se encontra possui características especiais: o português é para eles uma segunda língua, pois a língua de sinais é a sua primeira língua, só que o processo não é o de aquisição natural por meio da construção de diálogos espontâneos, mas o de aprendizagem formal na escola. $O$ modo de ensino/aprendizagem da língua portuguesa será, então, o português por escrito, ou seja, a compreensão e a produção escritas, considerando-se os efeitos das modalidades e 0 acesso a elas pelos surdos. (SALLES et al., 2004, p. 115).

Nesse sentido, é preciso que a pessoa surda tenha uma disciplina específica para ensinar a língua portuguesa na sua modalidade escrita, em todos os segmentos em que haja estudantes surdos.

Uma educação bilíngue é mais que a presença de profissionais que usam a Libras é preciso observar:

Como falar de bilinguismo na educação deixando de lado estas questões que envolvem o conceito de educação, em seu sentido mais amplo e objetivo? O que propomos é uma reflexão sobre o processo educacional do surdo, não no sentido pedagógico mais restrito do termo, mas no que se refere ao seu desenvolvimento como indivíduo em si mesmo e à sua participação como indivíduo na sociedade. Evidentemente, nossa experiência na área, aponta para diversas direções. Vemos, por um lado, caminhos mais lúcidos que respeitam o surdo e sua cultura e, portanto, encaram o bilinguismo na educação como um todo nunca dissociado de um projeto educacional - que envolve a comunidade de surdos e inclui não só os educadores, mas o familiar quer sejam surdos ou ouvintes, e que se estende ao meio social em que vive este indivíduo, de modo a estimular e a atuar no sentido de propiciar a interlocução constante. (FERNANDES, 2003, p. 54).

É na verdade uma tomada de decisão de política educacional que democratiza o direito à educação a pessoa surda, a comunidade local e a sociedade brasileira em geral, sendo o uso das duas línguas o maior princípio educacional inclusivo e que vamos observar que será o encaminhamento normativo recente no cenário brasileiro. 
A Constituição Federal no art. 22, XXIV diz que é competência privativa da União legislar sobre as diretrizes e bases da educação nacional, assim como, no seu art. 24, IX estabeleceu competência concorrente entre a União, os Estados e o Distrito Federal legislar sobre educação e no art.30, IV a competência dos munícipios em manter, através de financiamento e cooperação técnica da União e dos estados, os programas da educação infantil e do ensino fundamental.

Com base no texto constitucional pátrio que a LDB/98 instituiu a competência e obrigatoriedade da União em elaborar o Plano Nacional de Educação - PNE em colaboração com os Estados, os Distrito Federal e os Municípios brasileiros, conforme o art. 9², I da LDB. Já no art. 10, III incube aos Estados a elaboração e execução de políticas e planos educacionais em sintonia com o PNE, integrando e coordenando as suas ações com a dos municípios, que, no art. 11, I deve organizar, manter e desenvolver seu sistema de ensino, integrado e em colaboração com o Estado e a União, que em simetria aos demais entes políticos, deverá elabora e implementar seu Plano Municipal de Educação.

O prazo de vigência desses planos educacionais é de 10 anos conforme 0 art.87, $\S 1^{\circ}$ da LDB/96.

Continuaremos a descrição e análise do reflexo normativo da LDB/96 nos planos educacionais em vigor, nas metas e estratégias que asseguram a especificidade da educação da pessoa surda com o objetivo de demonstrar a vontade democrática e a posição política jurídica que se adotou e, ao mesmo tempo, sobre àquelas que foram normatizada pela União, pelo Estado da Bahia e pelo Município de Salvador em razão do contexto reflexivo desse trabalho e coerência jurídica consagrada pela constituição e pela lei de diretrizes e bases da educação nacional em vigor que estabeleceram a complementariedade entre os Entes Políticos no que tange a matéria de educação.

O PNE, aprovado pelo Congresso Nacional com Lei no 13.005/2014, estabeleceu como política educacional para a pessoa surda em escolas e as classes bilíngues e em escolas inclusivas, como podemos observar na meta 4 e a estratégia 4.7:

Meta 4: universalizar, para a população de 4 (quatro) a 17 (dezessete) anos com deficiência, transtornos globais do desenvolvimento e altas habilidades ou superdotação, o acesso à educação básica e ao atendimento educacional especializado, preferencialmente na rede regular de ensino, com a garantia de sistema educacional inclusivo, de salas de recursos multifuncionais, classes, escolas ou serviços especializados, públicos ou conveniados.

4.7) garantir a oferta de educação bilíngue, em Língua Brasileira de Sinais - LIBRAS como primeira língua e na modalidade escrita da Língua Portuguesa como segunda língua, aos (às) alunos (as) surdos e com deficiência auditiva de 0 (zero) a 17 (dezessete) anos, em escolas e classes bilíngues e em escolas inclusivas, nos termos do art. 22 do Decreto $n^{\circ}$ 5.626, de 22 de dezembro de 2005, e dos arts. 24 e 30 da Convenção sobre os Direitos das Pessoas com Deficiência, bem como a adoção do Sistema Braille de leitura para cegos e surdos-cegos (PNE, 2014) 
A ordem em que aparecem no texto legal nos leva a entender que a escola e a classe bilíngue (Libras e Português escrito) deve ser a opção legislativa e a escola inclusiva na impossibilidade de isso se efetivar, sendo a preferência em rede regular e no sistema público de educação, ou seja, nos lugares em que tenham estudantes surdos que possa formar uma escola bilíngue será uma escola bilíngue; não sendo possível formar uma escola mas uma classe, essa será uma classe bilíngue em uma escola de ouvintes e na impossibilidade de formar uma escola ou uma classe bilíngue, será em uma escola inclusiva.

Esse reconhecimento ampliativo e inclusivo para a pessoa surda é a garantia constitucional do direito coletivo e individual à educação no Brasil.

No Plano Estadual de Educação da Bahia - PEE/BA, aprovado pela Lei no. 13.559/2016, ratificará essa meta e estratégia:

Meta 4: Universalizar, para a população de 04 (quatro) a 17 (dezessete) anos com deficiência, transtornos globais do desenvolvimento e altas habilidades, o acesso à Educação Básica e ao atendimento educacional especializado, nas redes regulares de ensino, com a garantia de sistema educacional inclusivo, de salas de recursos multifuncionais, classes, escolas ou serviços especializados, públicos ou conveniados, até o último ano de vigência deste PEE-BA.

4.7) estimular a oferta de educação bilíngue, em Língua Brasileira de Sinais - LIBRAS, como primeira língua, e na modalidade escrita da Língua Portuguesa, como segunda língua, aos estudantes surdos e com deficiência, em escolas e classes bilíngues e em escolas inclusivas, nos termos do que dispõe o Decreto Federal no 5.626, de 22 de dezembro de 2005, e os arts. 24 e 30 da Convenção Internacional sobre os Direitos das Pessoas com Deficiência, promulgada pelo Decreto Federal oㅜ 6.949, de 25 de agosto de 2009, bem como a adoção do Sistema Braille de leitura para cegos e surdoscegos. (PEE/BA, 2016)

Já o Plano Municipal de Educação de Salvador - PME/SSA, aprovado pela LEI № 9105/2016, não trouxe a previsão de escolas inclusivas, ou seja, estabeleceu que as escolas e classes bilíngues são as duas formas de efetivar o direito a educação da pessoa surda:

Meta 4: Universalizar, para todos os estudantes com deficiência, transtornos globais do desenvolvimento e altas habilidades ou superdotação, matriculados na rede, o acesso à Educação Básica e ao atendimento educacional especializado, preferencialmente na rede regular de ensino, com a garantia de sistema educacional inclusivo, de salas de recursos multifuncionais, classes, escolas ou serviços especializados, públicos ou conveniados.

4.8 garantir a oferta de educação bilíngue em Língua Brasileira de Sinais - LIBRAS como primeira língua e na modalidade escrita da Língua Portuguesa como segunda língua aos alunos surdos e com deficiência auditiva, em escolas e classes bilíngues, nos termos do art. 22 do Decreto $n^{0} 5.626$, de 22 de 
dezembro de 2005, e dos artigos 24 e 30 da Convenção sobre os Direitos das Pessoas com Deficiência, bem como a adoção do Sistema Braille de leitura para cegos e surdos-cegos (PME/SSA, 2016).

Como podemos perceber nos planos educacionais em razão das articulações dos movimentos sociais surdos, a educação da pessoa surda deve acontecer sobre a égide da escolas e classes bilíngues e, na impossibilidade disso acontecer, em escola inclusiva, quando deve incidir, imediatamente, todos os dispositivos jus-educacionais protetivo ao direito da pessoa surda à educação, que além da LDB/96 e seus reflexos normativos, devem ser extraídos da Lei 13.146/2015, mais conhecida como a Lei Brasileira de Inclusão.

\section{CONSIDERAÇÕES FINAIS}

A nossa representação social de educação, currículo disciplinar, escola e classe escolar é resultado de um processo histórico excludente, em que diversos sujeitos humanos foram alijados e com base nisso que nossas edificações escolares foram/são erguidas.

Conscientes dessa assertiva fizeram/fazem os diversos movimentos sociais empreenderam em suas bandeiras políticas a disputa do que é educação, escola e classe escolar, impulsionando tensões que levaram a produções jus-educacionais que alteram o modo monocultural que percebemos a escola, no seu plural, escolas.

Diferentes espaços educativos que tenham como função social a garantia constitucional do direito à educação, com igualdade e respeito a diferença.

É nesse sentido que a palavra educação é polissêmica, que não se reduz aos espaços escolares formais, que não se apresenta da mesma forma diante da diversidade e da diferença que marca a nossa sociedade.

Essa diversidade de pessoas que lutam de maneira coletiva para pautar suas reinvindicações e, baseados na constituição cidadã, impuseram alterações legislativas importantes que atendam suas especificidades educacionais, como podemos observar, ao longo desse trabalho, demonstrando que já há uma produção normativa que, em busca de uma processo educacional efetivamente inclusivo, fizeram discriminação positiva e modularam as práticas educativas e seus lugares de acontecimentos diante da pessoa surda.

Adentramos as dinâmicas históricas da educação da pessoa surda para estabelecermos a relevância das escolas bilíngues (L1 Língua de sinais e L2 Língua portuguesa na sua modalidade escrita) no desenvolvimento educacional da pessoa surda e descrevemos os dispositivos legais educacionais que foram impactados pela Lei 10.436/2002 e pelo Decreto 5.626/2005 conjuntamente com a lei 13.146/2015 em que concluímos que a opção legislativa positivada em lei é pelas escolas e classes bilíngue para surdos.

Podemos constatar que os PNE (Lei nำ13.005/2014), PEE/BA (Lei no․ 13.559/2016) e PME/SSA (LEI № 9105/2016) já colocaram em suas metas e estratégias as escolas e as classes bilíngues na educação das pessoas surdas. 
Dessa forma, entendemos que o processo de ensino aprendizagem deve estar pautado com vista a possibilitar múltiplas formas, múltiplas maneiras para múltiplos sujeitos educacionais.

Então, debater a educação de surdos de forma especializada, não é algo inovador, já existe e está amparada em diversos diplomas legais.

Isso não entra em conflito com a ideia da inclusão, não significa segregação, pelo contrário significa adequação, a garantia de ter uma educação própria, especializada e que possibilite que a educação seja instrumento para cidadania, pelo viés da igualdade formal, mas sobretudo, da igualdade material entre as pessoas surdas e não surdas.

No caso da pessoa surda é em quaisquer espaços educativos que a incidência da perspectiva bilíngue, sendo a Libras a língua de instrução, deve acontecer imediatamente para que não haja prejuízo na efetivação do seu direito à educação, tanto nos espaços públicos quantos nos espaços privados.

Somente na garantia das escolas e classes bilíngues é que haverá a igualdade material entre pessoas surdas e não surdas, com respeito ao direito linguístico e ao acesso pleno aos saberes, estaremos diante da perspectiva inclusiva na seara educacional para a pessoa surda.

\section{REFERÊNCIAS}

BENTO, Nanci Araujo. Educação Inclusiva Para Surdo: verdade ou ficção? in: Múltiplos atores e Saberes na Educação de Surdos. VIII Congresso Internacional e XIV Seminário Nacional do INES. Rio de Janeiro, setembro de 2009.

BRASIL. Constituição Federal (1988). Constituição da República Federativa do Brasil. Texto constitucional promulgado em 5 de outubro de 1988, com as alterações adotadas pelas Emendas Constitucionais. Portal da Legislação, Brasília.

BRASIL. Instituto Nacional de Estudos e Pesquisas Educacionais Anísio Teixeira. Plano Nacional de Educação PNE 2014-2024: Linha de Base. Brasília, DF: Inep, 2015. 404 p.: il.

BRASIL. Lei n.10.436, de 24 de abril de 2002. Dispõe sobre a Língua Brasileira de Sinais - Libras e dá outras providências.

BRASIL. Decreto de Lei n. 5.626, de 22 de dezembro de 2005. Regulamenta a Lei oㅜ 10.436, de 24 de abril de 2002, que dispõe Sobre a Língua Brasileira de Sinais - Libras, e o art. 18 da Lei n. 10.098, de 19 de dez. 2000.

CAMPELLO, A. R. e S. Aspectos da visualidade na educação de Surdos. Tese de Doutorado (Educação). Santa Catarina: Universidade Federal de Santa Catarina, 2008.

CAMPELLO, A. R.; REZENDE, P. L. F. Em defesa da escola bilíngue para surdos: a história. Educar em Revista, Curitiba, Brasil, Edição Especial n. 2/2014, p. 71-92. Editora UFPR. 
CANDAU, V. Pluralismo cultural, cotidiano escolar e formação de professores. In: (org.). Magistério: construção cotidiana. Petrópolis, RJ: Vozes, 1997.

FOUCAULT, Michel. As palavras e as coisas. São Paulo: Martins Fontes por acordo com Portugália Editora Ltda, 1967.

FREIRE, Paulo. Pedagogia do Oprimido. Rio de Janeiro: Paz e Terra, 2004, 42. ㄹ. edição.

GADOTTI, Moacir; ROMÃO. E.José. Autonomia da Escola: Princípios e Propostas. 4 ed - São Paulo: Cortez, 2001.

GIL, Antonio Carlos. Como elaborar projetos de pesquisa. 4. ed. São Paulo: Atlas, 2008.

HONNETH, A. Luta por reconhecimento: a gramática moral dos conflitos sociais. Trad. Luiz Repa. São Paulo: editora 34, 2003.

LEBER. Werner Schror. Libras: Oralismo, Comunicação Total e Bilinguismo. [S.I.]. 2017.

NOGARO, Arnaldo. Reflexão Sobre Pressupostos Que Norteiam o Projeto Político Pedagógico da Escola. Perspectiva. Erechim. V.19, no 67 - 74, setembro 1995.

O tradutor e intérprete de língua brasileira de sinais e língua portuguesa / Secretaria de Educação Especial; Programa Nacional de Apoio à Educação de Surdos - Brasília: MEC; SEESP, 2004. 94 p.: il.

PEREIRA, Alex Sandrelanio dos Santos. Cultura e educação Sociocomunitária: uma perspectiva para o ensino de história e surdez/ Alex Sandrelanio dos Santos Pereira. - Americana: Centro Universitário Salesiano de São Paulo, 2015. $125 \mathrm{f}$.

PERLIN, G. Identidades surdas. In: SKLIAR, C. A surdez: um olhar sobre as diferenças. Porto Alegre: Editora Mediação, 1998.

QUADROS. Ronice Muller de, KARNOPP. Lodenir Becker. Língua de sinais brasileira: estudos linguísticos. Porto Alegre: Artmed. 2004.

SKLIAR, C. Discursos y práticas sobre a deficiência y normalidad. Lãs exclusiones del lenguaje, del grupou de la mente. In: GENTILI, P. Códigos para la ciudadania. La formación ética como prática de la libertad. Madrid/Buenos Aires:Santillana, 2000.

SKLIAR, C. Educação e exclusão. Abordagens sócio-antropológicas em educação especial. Porto Alegre: Editora Mediação, 1997. 
SKLIAR, Carlos. Os estudos surdos em educação: problematizando a normalidade. In: (Org.). A surdez: um olhar sobre as diferenças. Porto Alegre: Mediação, 2010, p. 7-32.

STROBEL. Karin. As imagens do outro sobre a cultura surda. 4.ed. 1.reimp. Florianópolis: Ed. Da UFSC. 2018.

STROBEL. Karin. História da Educação de Surdos. Florianópolis. 2009.

VEIGA, Ilma Passos A. (Org). Projeto Político Pedagógico da Escola: uma construção possível. 3.ed. Campinas: Papirus Editora, 1995. 